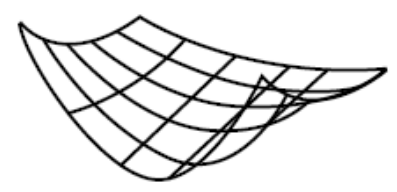

UNIVERSITY OF

TECHNOLOGY SYDNEY

QUANTITATIVE FINANCE

RESEARCH CENTRE

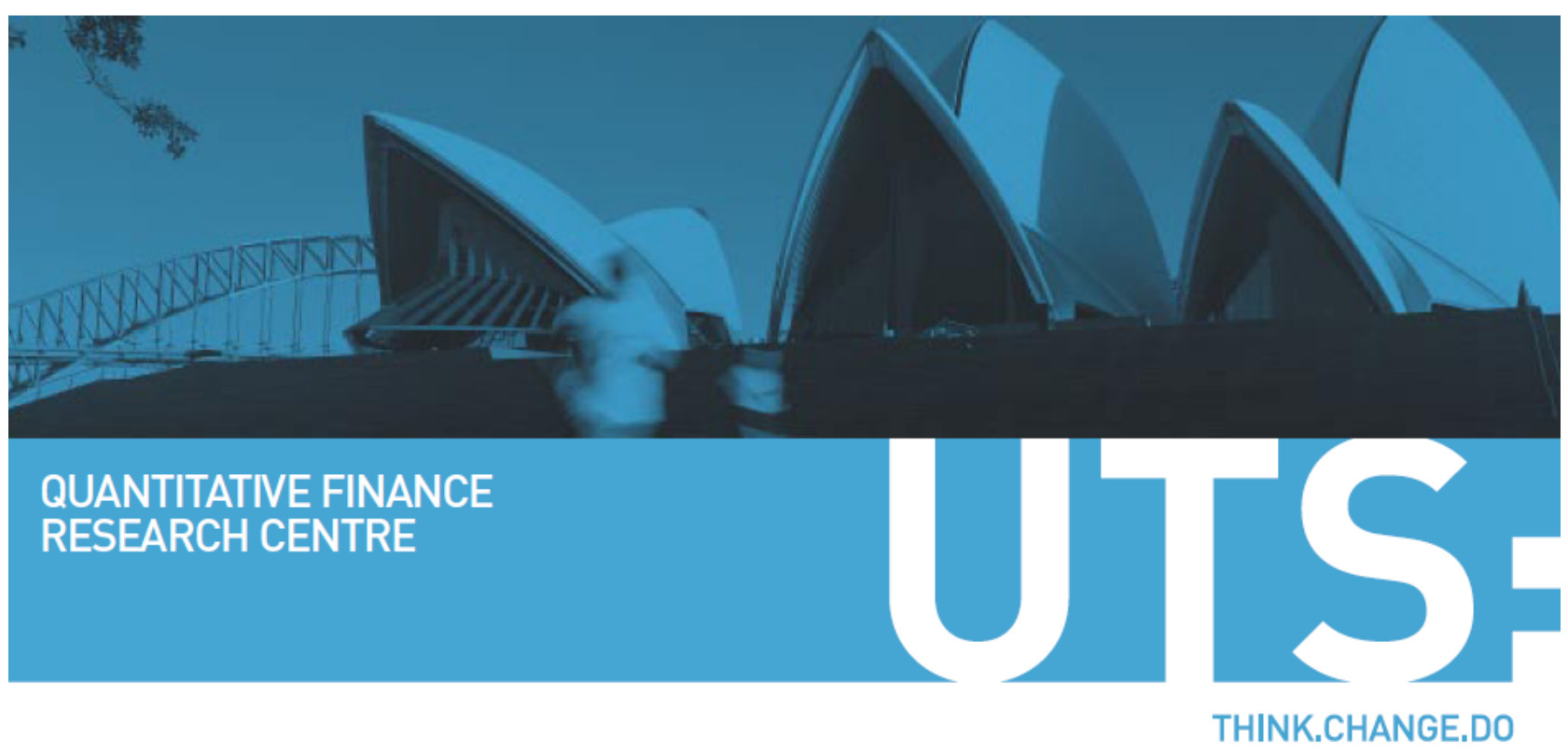

QUANTITATIVE FINANCE RESEARCH CENTRE

Research Paper 262

November 2009

Real World Pricing of Long Term Contracts

Eckhard Platen

ISSN 1441-8010

www.qfrc.uts.edu.au 


\title{
Real World Pricing of Long Term Contracts
}

\author{
Eckhard Platen ${ }^{1}$
}

November 6, 2009

\begin{abstract}
Long dated contingent claims are relevant in insurance, pension fund management and derivative pricing. This paper proposes a paradigm shift in the valuation of long term contracts, away from classical no-arbitrage pricing towards pricing under the real world probability measure. In contrast to risk neutral pricing, the long term excess return of the equity market, known as the equity premium, is taken into account. Further, instead of the savings account, the numéraire portfolio is used, as the fundamental unit of value in the analysis. The numéraire portfolio is the strictly positive, tradable portfolio that when used as benchmark makes all benchmarked nonnegative portfolios supermartingales, which means intuitively that these are downward trending or at least trendless. Furthermore, the benchmarked real world price of a benchmarked claim is defined to be its real world conditional expectation. This yields the minimal possible price for its hedgable part and minimizes the variance of the benchmarked hedge error. The pooled total benchmarked replication error of a large insurance company or bank essentially vanishes due to diversification. Interestingly, in long term liability and asset valuation, real world pricing can lead to significantly lower prices than suggested by classical no-arbitrage arguments. Moreover, since the existence of some equivalent risk neutral probability measure is no longer required, a wider and more realistic modeling framework is available for exploration. Classical actuarial and risk neutral pricing emerge as special cases of real world pricing.
\end{abstract}

Key words and phrases: long term pricing, real world pricing, risk neutral pricing, numéraire portfolio, law of the minimal price, strong arbitrage, hedge simulation, diversification, liquidity premium.

\footnotetext{
${ }^{1}$ University of Technology, Sydney, School of Finance \& Economics and Department of Mathematical Sciences, PO Box 123, Broadway, NSW, 2007, Australia
} 


\section{Introduction}

Long dated contingent claims are relevant in insurance, pension fund management and derivative pricing. This paper proposes a paradigm shift in the valuation of long term contracts, away from classical no-arbitrage pricing, towards pricing under the real world probability measure. In contrast to risk neutral pricing, the long term excess return of the equity market, known as the equity premium, is taken into account. Further, instead of the savings account, the numéraire portfolio is used as the fundamental unit of value in the analysis. The numéraire portfolio is the strictly positive, tradable portfolio that when used as a benchmark makes all benchmarked nonnegative portfolios supermartingales. This means their current benchmarked value is greater than, or equal to its expected future benchmarked values. Furthermore, the benchmarked real world price of a benchmarked claim is defined to be its real world conditional expectation. This yields the minimal possible price for its hedgable part and minimizes the variance of the benchmarked hedge error. It is shown that the pooled total benchmarked replication error of a large insurance company or bank essentially vanishes due to diversification. Interestingly, in long term liability and asset valuation, real world pricing can lead to significantly lower prices than suggested by classical no-arbitrage arguments. Moreover, since the existence of some equivalent risk neutral probability measure is no longer required, a wider and more realistic modeling framework may be explored. Classical actuarial and risk neutral pricing emerge as special cases of real world pricing.

In recent years the problem of accurately valuing the long term assets and liabilities held by insurance companies, banks and pension funds has become increasingly important. How these institutions perform such valuations often remains unclear. However, the recent experience with mortgage-backed securities and credit derivatives suggests they do sometimes get these valuations wrong. One possible explanation, which we explore in this article, is that the risk neutral pricing paradigm itself may be inherently flawed, especially when it is applied to the valuation of long dated claims.

The academic literature on the valuation of contingent claims is very rich, and stretches from the traditional actuarial approach to various equilibrium-style valuation concepts, including risk neutral pricing and related no-arbitrage pricing methods. As this literature has developed, various concepts, such as deflators, pricing kernels, state-price densities and stochastic discount factors, have been introduced. However, what has been missing is an overarching framework for studying and comparing these methods and for performing the essential task of long term valuation in a consistent and robust manner. The benchmark approach, developed in Platen \& Heath (2006), proposes such a framework. Instead of relying on the domestic savings account as the reference unit, the best performing, tradable strictly positive portfolio, namely the numéraire portfolio, whose origin can be traced back to Long (1990), is chosen as numéraire. Since the existence 
of an equivalent risk neutral probability measure is no longer postulated, a wider and more realistic modeling framework becomes available. In particular, the underlying idea of the benchmark approach is to denominate all quantities in units of the numéraire portfolio, and to examine them under the real world probability measure.

Philosophically, the benchmark approach suggests a move from an abstract form of relative pricing to an economically motivated, transparent form of absolute pricing. As opposed to risk neutral pricing, the long term excess return of the equity market, known as the equity premium, plays an important role in the analysis.

The benchmarked real world price of a benchmarked claim is defined as its real world conditional expectation. Due to the supermartingale property of any nonnegative benchmarked portfolio it provides the minimal possible price for its hedgable part and minimizes the variance of the benchmarked hedge error. The latter can be essentially removed via diversification when pooled. It is worth emphasizing the fact that real world pricing can lead to significantly lower prices for variable annuities than suggested by standard no-arbitrage arguments. The acknowledgement of the presence of the equity premium under the benchmark approach is likely to make a range of long term insurance and pensions products more affordable.

This paper will avoid technicalities and focusses on an explanation of the key elements of the paradigm shift, represented by the benchmark approach, the core statements of which are model independent and, therefore, extremely robust.

The structure of the paper is as follows: Section 2 gives a brief survey on the literature about pricing methods in insurance and finance for variable annuities. Section 3 introduces the benchmark approach. Real world pricing is described in Section 4. Two examples on real world pricing of long term contracts are illustrated in Sections 5 and 6, and Section 7 concludes.

\section{Valuation Methods for Variable Annuities}

One of the most dynamic areas in the current risk management literature is the valuation of variable annuities. These represent long term contracts with payoffs that depend on insured events and on underlying assets that are traded in financial markets. There is an increasing literature on the pricing of variable annuities which we briefly survey in this section. The aim is to list established pricing methods without aiming for completeness.

Various valuation principles have been proposed by different authors and sometimes even by the same author. One of the earliest articles treated variable annuities from an actuarial perspective in Sloane (1970). The appropriate mod- 
eling of the long term evolution of stochastic equity markets for actuarial use has been analyzed, for instance, in Wise (1984b), Wilkie (1985, 1987, 1995), Schmidli (1995), Bilodeau (1997), Boyle \& Hardy (1997, 2003), Wirch \& Hardy (1999), Tiong (2000), Cairns (2001), Hardy (2003) and Wüterich, Bühlmann \& Furrer (2008). The papers by Bernard (1993), Mitchell (1994) and Ravindran \& Edelist (1996) discuss the implications of various actuarial modeling assumptions.

The matching of well-defined cash flows with liquidly traded ones, while minimizing the risk of reserves, has been a widely used pricing method in insurance. For instance, Wise (1984a, 1984b, 1987a, 1987b, 1989), Wilkie (1985) and Keel \& Müller (1995) study contracts when a perfect match is not possible.

The main stream of the research, however, follows the concept of no-arbitrage pricing, in the sense of Ross (1976) and Harrison \& Kreps (1979). This approach has been widely used in finance, where it appears in the guise of risk neutral pricing. The earliest applications of no-arbitrage pricing to variable annuities are the papers by Brennan \& Schwartz (1976, 1979) and Boyle \& Schwartz (1977). These authors extended Black-Scholes-Merton option pricing (see Black \& Scholes (1973) and Merton (1973)) to the case of equity-linked insurance contracts. After more than 35 years of development no-arbitrage remains the dominant pricing paradigm for variable annuities linked to financial assets. Other papers worth mentioning in this regard include Delbaen (1986), Bacinello \& Ortu (1993, 1994, 1996), Briys \& Varenne (1997), Pennachi (1999), Boyle, Kolkiewicz \& Tan (2001), Jorgensen (2001, 2004), Milevsky \& Posner (2001), Milevsky \& Salisbury (2001, 2006), Melnikov, Volkov \& Nechaev (2002), Melnikov (2003, 2004c), Pelsser (2003), Tanskanen \& Lukkarinen (2003), Hürlimann (2004), De Felice \& Moriconi (2005), Siu (2005), Biffis \& Millosovich (2006), Milevsky, Moore \& Young (2006), Chu \& Kwok (2006, 2007), Bauer, Kling \& Russ (2007) and Kling, Richter \& Russ (2007) for European style payoffs; and Grosen \& Jorgensen (1997, 2000, 2002), Bacinello (2001, 2005), Ballotta, Haberman \& Wang (2003), Vannucci (2003), Ballotta (2004) and Costabile, Massabo \& Russo (2007) for Americantype contracts. The effect of stochastic interest rates on the risk neutral value of a guarantee has been discussed, for instance, in Bacinello \& Ortu (1993, 1996), Aase \& Persson (1994), Albizzati \& Geman (1994), Nielsen \& Sandmann, (1995, 1996, 2008), Ekern \& Persson (1996), Persson \& Aase (1997), Miltersen \& Persson (1999) and Huang \& Cairns (2004, 2005).

In reality, one has to deal with the fact that markets are incomplete and the choice of a risk neutral pricing measure is, therefore, not unique, as pointed out by Föllmer \& Sondermann (1986), Föllmer \& Schweizer (1991), Hofmann, Platen \& Schweizer (1992), Gerber \& Shiu (1994), Gerber (1997) and Jaimungal \& Young (2005). Duffie \& Richardson (1991) and Schweizer (1992) address this issue by suggesting certain mean-variance hedging methods based on a form of varianceor risk-minimizing objective, assuming the existence of a particular risk neutral measure. In the latter case, the so-called minimal equivalent martingale measure, due to Föllmer \& Schweizer (1991), emerges as the pricing measure. It allows 
for the pricing of all non-traded risk under the real world probability measure, but changes the pricing measure for traded risk to a risk neutral measure. This valuation method is also known as local risk minimization and was considered by Möller (1998, 2001), Schweizer (2001) and Dahl \& Möller (2006) for the valuation of insurance products.

We draw the reader's attention to the study by Windcliff, Forsyth \& Vetzel (2001), which investigated reset and optional features in variable annuities, under the assumptions of the risk neutral approach. These authors conclude that some insurers may be underpricing certain guarantees, since the risk neutral prices appear to be higher than those charged in the market. It will become clear that the risk neutral price of a claim can be well above the economically correct price under the real world pricing approach, which we develop in Section 4.

Following the ideas of Föllmer \& Leukert (1999, 2000), the pricing and hedging of equity-linked insurance products using shortfall risk or quantile hedging has been studied by Krutchenko \& Melnikov (2001), Melnikov (2004a, 2004b, 2004c), Melnikov, Romaniuk \& Skornyakova (2005), Melnikov \& Skornyakova (2005), Melnikov \& Romaniuk (2006) and Wang (2009).

Another approach involves the maximization of expected terminal utility, see Karatzas et al. (1991), Kramkov \& Schachermayer (1999) and Delbaen et al. (2002). In this case the valuation of variable annuities is based on a particular form of utility indifference pricing. This form of valuation has been applied to the problem of derivative pricing subject to transaction costs by Hodges \& Neuberger (1989) and later by Davis (1997). It has been used to value equitylinked insurance products by Young \& Zariphopoulou (2002, 2002), Young (2003) and Moore \& Young (2003). In Jaschke \& Küchler (2001) "good-deal" bounds for valuation purposes have been suggested, which go back to Cerny \& Hodges (1999). They aim to fill the gap between classical arbitrage pricing and expected utility maximization.

There is an ongoing debate on the links between the valuation of insurance liabilities and financial economics, for which the reader may refer to Reitano (1997), Longley-Cook (1998), Babbel \& Merrill (1998), Möller (1998, 2002), Phillips, Cummins \& Allen (1998), Girard (2000), Lane (2000) and Wang (2000). Equilibrium modeling from a macro-economic perspective has been the focus of another major line of research that can be traced back to Debreu (1982). Duffie (2001) and Starr (1997), among others, studied the existence of a market equilibrium and Pareto efficiency, which has links to expected utility maximization.

Note that stochastic mortality rates are easily incorporated in the pricing of insurance products as demonstrated by Milevsky \& Promislow (2001), Dahl (2004), Kirch \& Melnikov (2005), Cairns, Blake \& Dowd (2006a, 2006b, 2008), Biffis (2005), Melnikov \& Romaniuk (2006, 2008) and Jalen \& Mamon (2008). Most of these authors assume that the market is complete with respect to mortality risk, which means that it can be removed by diversification, as a result of the Law of 
Large Numbers.

Several no-arbitrage pricing concepts have been developed in finance that are equivalent to the risk neutral approach under certain assumptions. For instance, Cochrane (2001) employs the notion of a stochastic discount factor. The use of a state-price density, a deflator or a pricing kernel have also been considered by Constantinides (1992), Cochrane (2001) and Duffie (2001). Another form of no-arbitrage pricing was pioneered by Long (1990) and further developed by Bajeux-Besnainou \& Portait (1997) and Becherer (2001). It uses the numéraire portfolio as numéraire, instead of the savings account, and employs the real world probability measure as the pricing measure. This line of research comes closest to the real world pricing proposed in this paper. The primary difference is that we do not assume the existence of an equivalent risk neutral probability measure. In so doing we allow for a much richer class of models to be available for consideration.

The version of the Fundamental Theorem of Asset Pricing obtained by Delbaen \& Schachermayer (1998) establishes a correspondence between the "no free lunch with vanishing risk" no-arbitrage concept and the existence of an equivalent risk neutral probability measure. This important result demonstrates that classical no-arbitrage pricing is based on the restrictive assumption that an equivalent risk neutral probability measure must exist. More precisely, the (Radon-Nikodym derivative) density process of the corresponding risk neutral pricing measure is assumed to be a martingale. As we will see, a major consequence of this assumption is that classical no-arbitrage pricing methods ignore the real world long term trend of the equity market above that of the savings account and represent a form of relative pricing. Thus, the presence of the highly relevant equity premium is neglected. The existence of the equity premium is what makes long term investments in the stock market worthwhile. Therefore, it should play a significant role in the valuation of long term contingent claims. For the valuation of short term contracts the presence of the equity premium does not matter much and classical risk neutral pricing gives reasonable results. However, as we shall see in Sections 5 and 6, for long dated payoffs there may exist significantly cheaper self-financing hedge portfolios that exploit systematically the equity premium.

As alluded to above, what is missing from the literature is a pricing framework that takes into account the long term equity risk premium. Such a concept, presented in Section 4, has been developed in Platen (2002), Bühlmann \& Platen (2003), Platen \& Heath (2006) and Platen (2006). It chooses the best-performing, strictly positive, tradeable portfolio as benchmark and makes it the central object for modeling. The restrictive assumption of the existence of an equivalent risk neutral probability measure is no longer required, in contrast to Long (1990), Bajeux-Besnainou \& Portait (1997) and Becherer (2001). Instead, all pricing is done with respect to the real world probability measure, and the approach is, therefore, labelled "real world pricing".

Real world pricing generalizes risk neutral pricing and other no-arbitrage pricing 
theories. It also generalizes actuarial pricing, as will be demonstrated in Section 4 . Most recent detailed results on the role of the numéraire portfolio, the central building block of the benchmark approach, can be found in Karatzas \& Kardaras (2007) and Kardaras \& Platen (2008). An application of real world pricing to the valuation of variable annuities, in a case when no equivalent risk neutral probability measure exists, has been presented by Marquardt, Platen \& Jaschke (2008). Sections 5 and 6 give illustrative examples for the pricing of long dated contingent claims.

\section{Benchmark Approach}

This section introduces the benchmark approach, which allows the formulation of the concept of real world pricing. The key idea is that there exists a best performing strictly positive tradable portfolio in the given investment universe. This benchmark portfolio can be interpreted and used as a universal currency. It allows the formulation of powerful results about diversification, portfolio optimization and contingent claim valuation.

We begin by considering a market comprising a finite number of primary security accounts. An example of such an instrument could be an account containing shares of a company with all dividends reinvested in that stock. A savings account held in any currency is another example of a primary security account.

Continuous time models can provide a compact and elegant mathematical description of asset dynamics. However, in reality, continuous trading is not possible. The time interval between potential trading times, as facilitated by electronic exchanges, can become extremely small. To be realistic, we consider a countable set of potential trading times $0=t_{0}<t_{1}<\ldots$, which can be random and are assumed to be observable, where $\lim _{n \rightarrow \infty} t_{n} \stackrel{\text { a.s. }}{=} \infty$ almost surely. Note that discretely observed continuous time models can be employed in our general framework.

The benchmarked value of a security represents its value, when denominated in units of the benchmark, which we assume to exist and characterize later as the numéraire portfolio. Denote by $\hat{S}_{t_{n}}^{j}$ the benchmarked value of the $j$ th primary security account, $j \in\{0,1, \ldots\}$, at time $t_{n} \geq 0, n \in\{0,1, \ldots\}$. The particular dynamics of the primary security accounts are not important for the main results. Taxes and transaction costs are neglected for simplicity.

The market participants can form self-financing portfolios with primary security accounts as constituents. A portfolio at time $t_{n}$ is described by the number $\delta_{t_{n}}^{j}$ of units held in the $j$ th primary security account, $j \in\{1,2, \ldots\}, n \in\{0,1, \ldots\}$. Assume that for all $n \in\{0,1, \ldots\}$ the values $\delta_{t_{n}}^{0}, \delta_{t_{n}}^{1}, \ldots$, for any given strategy $\delta=\left\{\delta_{t_{n}}=\left(\delta_{t_{n}}^{0}, \delta_{t_{n}}^{1}, \ldots\right)^{\top}, n \in\{0,1, \ldots\}\right\}$, depend only on information available at the potential trading time $t_{n}$. The value of the benchmarked portfolio, which 
means its value denominated in units of the benchmark, is then given by

$$
\hat{S}_{t_{n}}^{\delta}=\sum_{j=0}^{\infty} \delta_{t_{n}}^{j} \hat{S}_{t_{n}}^{j},
$$

$n \in\{0,1, \ldots\}$. Since there is only finite total wealth available in the market, we consider only strategies whose associated portfolios are finite at all potential trading times.

Let $E_{t_{n}}(X)$ denote the expectation of a random variable $X$ under the real world probability $P$, conditioned on the information available at time $t_{n}$, see Shiryaev (1984). The main assumption that the benchmark approach imposes is the following:

Assumption 3.1 There exists a strictly positive benchmark portfolio, which makes each benchmarked nonnegative portfolio $\hat{S}_{t_{n}}^{\delta}$ a supermartingale. In other words, we have

$$
\hat{S}_{t_{n}}^{\delta} \geq E_{t_{n}}\left(\hat{S}_{t_{n+1}}^{\delta}\right)
$$

for all $n \in\{0,1, \ldots\}$.

We refer to the relation above as the supermartingale property of benchmarked securities. The assumed benchmark coincides with the numéraire portfolio for the particular model settings studied by Long (1990) and Becherer (2001). Since we are only requesting the existence of the numéraire portfolio, that is condition (3.2), the benchmark approach reaches significantly beyond the risk neutral world.

It is obvious that when using the best performing portfolio as benchmark, the current observed benchmarked value of a nonnegative portfolio is greater than or equal to its expected future benchmarked values. This means intuitively, if there is any long term trend in a benchmarked nonnegative portfolio, then the trend can only point downward. Assumption 3.1 guarantees the main properties of nonnegative securities in a financial market. For example, it implies the absence of economically meaningful arbitrage, as discussed in Platen (2006).

It is easily shown that the benchmark portfolio, if it exists, is unique. To see this, consider two strictly positive portfolios that are supposed to be numéraire portfolios. The first portfolio, when expressed in units of the second one, must satisfy the supermartingale property (3.2). By the same argument, the second portfolio, when expressed in units of the first one, must also satisfy the supermartingale property. Consequently, by Jensen's inequality both portfolios must be identical, and the value process of a numéraire portfolio that starts at a given strictly positive value is unique. Due to possible redundancies in the set of primary security accounts, this does not imply uniqueness for the trading strategy that generates the benchmark portfolio. 
Note that we do not rely on continuous time semimartingales to drive asset prices in our setup. Only the discrete-time supermartingale property (3.2) needs to be satisfied. If one lets the trading frequency tend to infinity, then the resulting weak limit does not need to represent a semimartingale, which allows to model long-range dependence; see Mandelbrot \& Van Ness (1968).

Assumption 3.1 is satisfied for almost all reasonable financial market models. It simply asserts the existence of a best performing portfolio that does not "explode". The requirement that such a portfolio should not "explode" follows from basic arbitrage considerations. In Platen \& Heath (2006) condition (3.2) is verified for jump-diffusion markets. This type of model already covers a wide range of possible dynamics. We emphasize that we allow models that only satisfy the supermartingale property (3.2) at a discrete sequence of observable potential trading times. From a practical perspective this is reasonable since continuous trading is not possible in reality.

By referring to results in Platen (2005) and Le \& Platen (2006) one can say that the numéraire portfolio is not only a theoretical construct, but can be approximated by well diversified portfolios, e.g. the S\&P500 total return index when the investment universe represents the US equity market. The MSCI total return world index turns out to be a good proxy of the numéraire portfolio when the global market is modeled. Crucial is that under the benchmark approach a proxy of the numéraire portfolio becomes physically identified and plays later a role in valuation and hedging.

A special type of security emerges when equality holds in condition (3.2).

Definition 3.2 A security is called fair if its benchmarked value $\hat{V}_{t_{n}}, n \in$ $\{0,1, \ldots\}$, is the best forecast of its future benchmarked values, that is,

$$
\hat{V}_{t_{n}}=E_{t_{n}}\left(\hat{V}_{t_{n+1}}\right)
$$

for all $n \in\{0,1, \ldots\}$.

One can say that (3.3) represents the discrete-time martingale property of fair securities. The above notion of a fair security is based on a comparison with the best performing portfolio. This is different to many other notions for "fair" prices. Also note that the benchmark approach allows us to consider securities that are not fair. This important flexibility will be required when modeling the equity premium of the stock market.

\section{$4 \quad$ Real World Pricing}

As stated earlier, the primary difference between the benchmark approach and the risk neutral approach is the choice of numéraire. Here we use the numéraire 
portfolio for valuation, while the savings account is the chosen numéraire in the risk neutral approach. The supermartingale property (3.2) ensures that the expected return of a benchmarked nonnegative portfolio can be at most zero. In the case of a fair benchmarked portfolio, the expected return is precisely zero. The current benchmarked value of such a portfolio is, therefore, always the best forecast of its benchmarked future values at any possible future trading time.

It is well-known and quite intuitive that within a family of nonnegative supermartingales, which approach the same random value, the supermartingale with the smallest initial value is a martingale, see Shiryaev (1984). There can be many supermartingales that approach the same future random value. The martingale that matches the future random value is the minimal supermartingale. This fundamental fact allows us to deduce directly the following Law of the Minimal Price:

Theorem 4.1 (Law of the Minimal Price) If a fair portfolio replicates a given nonnegative payoff at an observable potential trading time, then this portfolio represents the minimal replicating portfolio among all nonnegative portfolios that replicate this payoff.

There may exist unfair self-financing hedge portfolios in a benchmark setting. Consequently, the classical Law of One Price does not hold, in general. Nevertheless the Law of the Minimal Price provides access to a consistent price system for any kind of derivative contract.

For a given hedgable payoff the corresponding fair hedge portfolio represents the least expensive hedge portfolio. From an economic point of view this is also the correct price in a competitive market. As we will see later, there may exist several self-financing portfolios that hedge one and the same payoff. Only the fair portfolio hedges the payoff at minimal cost. Pricing based purely on hedging via classical no-arbitrage arguments, see Ross (1976), may lead to more expensive prices than those given by the corresponding fair price. This fact will be demonstrated later in Sections 5 and 6 .

Now, let us consider the problem of pricing a given payoff. Define a benchmarked contingent claim $\hat{H}_{T}$ as a nonnegative payoff, which is expressed in units of the benchmark. It is assumed to have finite expectation

$$
E_{0}\left(\hat{H}_{T}\right)<\infty
$$

and has to be delivered at maturity $T=t_{N} \in\left\{t_{1}, t_{2}, \ldots\right\}$, which can be an observable, random potential trading time.

If for a benchmarked contingent claim $\hat{H}_{T}, T \in\left\{t_{1}, t_{2}, \ldots\right\}$, there exists a fair portfolio $S^{\delta_{H}}$ which replicates this claim at maturity $t_{N}=T$, that is $\hat{H}_{T}=\hat{S}_{T}^{\delta_{H}}$, 
then, by the Law of the Minimal Price, its minimal replicating price process is at time $t_{n} \in\left\{t_{0}, t_{1}, \ldots, t_{N}\right\}$ given by

$$
\hat{S}_{t_{n}}^{\delta_{H}}=E_{t_{n}}\left(\hat{H}_{T}\right)
$$

By multiplying both sides of equation (4.2) with the value of the benchmark at time $t$, which we denote by $S_{t_{n}}^{*}$ when denominated in domestic currency, we obtain the real world pricing formula

$$
S_{t_{n}}^{\delta_{H}}=\hat{S}_{t_{n}}^{\delta_{H}} S_{t_{n}}^{*}=S_{t_{n}}^{*} E_{t_{n}}\left(\frac{H_{T}}{S_{T}^{*}}\right)
$$

where $H_{T}=\hat{H}_{T} S_{T}^{*}$ is the payoff denominated in domestic currency.

Formula (4.3) is called the real world pricing formula because it involves the conditional expectation $E_{t_{n}}$ with respect to the real world probability measure. It requires only the existence of the numéraire portfolio and the finiteness of the expectation in (4.1). These are conditions that can hardly be weakened. At the end of this section we justify the real world pricing formula also as a natural pricing rule for nonhedgable claims.

An important special case of the real world pricing formula (4.3) arises when $H_{T}$ is independent of $S_{T}^{*}$. In this case one obtains the actuarial pricing formula

$$
S_{t_{n}}^{\delta_{H}}=P\left(t_{n}, T\right) E_{t_{n}}\left(H_{T}\right),
$$

which discounts with the fair zero coupon bond price

$$
P\left(t_{n}, T\right)=S_{t_{n}}^{*} E_{t_{n}}\left(\left(S_{T}^{*}\right)^{-1}\right) .
$$

The derivation of (4.4) from (4.3) exploits the fact that the expectation of a product of independent random variables equals the product of their expectations. The formula (4.4) has been used by actuaries for centuries to obtain net present values.

Now, let us highlight the link between real world pricing and risk neutral pricing. Risk neutral pricing uses the domestic savings account $B_{t_{n}}$ as numéraire. We can derive risk neutral prices from real world prices by rewriting the real world pricing formula (4.3) in the following form

$$
S_{t_{n}}^{\delta_{H}}=E_{t_{n}}\left(\frac{\Lambda_{T}}{\Lambda_{t_{n}}} \frac{B_{t_{n}}}{B_{T}} H_{T}\right)
$$

Here we employ the benchmarked normalized savings account $\Lambda_{t_{n}}=\frac{B_{t_{n}} S_{0}^{*}}{S_{t_{n}}^{*} B_{0}}$, which arises as the (Radon-Nikodym derivative) density process of the putative risk neutral measure $Q_{t_{n}}$ in a complete market model for the time horizon $t_{n}$.

For illustration, let us interpret the S\&P500 total return index as the benchmark and numéraire portfolio for the US equity market. Its monthly observations in 


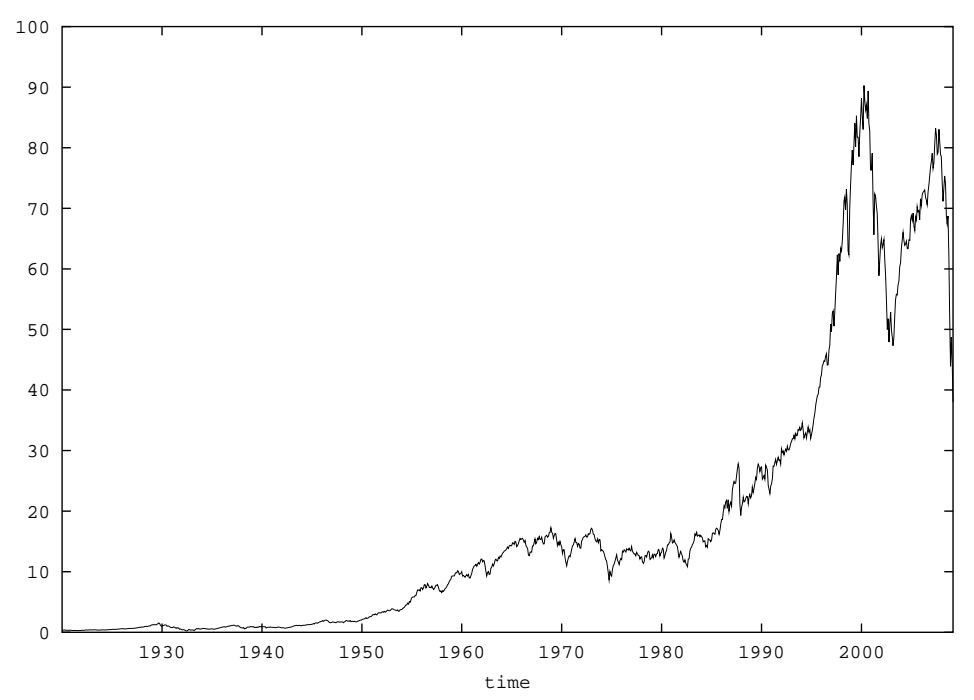

Figure 4.1: Discounted S\&P500 total return index.

units of the US savings account are displayed in Figure 4.1 for the period from 1920 until 2009.

This allows us to plot in Figure 4.2 the resulting density process of the putative risk neutral probability measure $Q_{t_{n}}$. Although we only have one sample path to work with, it seems highly unlikely that the path in Figure 4.2 is the realization of a martingale. It is much more likely to be the trajectory of a strict supermartingale, in which case the density process does not describe a probability measure. We will see this in Section 5 in an example by calculating the conditional expectation $E_{0}\left(\Lambda_{T}\right)$, which yields the total mass $Q_{T}(\Omega)$ of the putative risk neutral measure $Q_{T}$ for the time horizon $T>0$, where $\Omega$ denotes the set of all events.

For illustration, Figure 4.2 also displays the total mass of the putative risk neutral measure as a function of the time horizon $T$ assuming the minimal market model (MMM), which we describe in detail in Section 5. We only remark here that the MMM models the density process realistically as a strict supermartingale and not as a martingale. We will see that the putative risk neutral measure $Q_{T}$ is under the MMM not a probability measure since its total mass $Q_{T}(\Omega)$ is not the constant one but decreasing for increasing $T$. A substantial modeling error is made in long term valuations when assuming that the density process is a martingale. But this is the key assumption in classical no-arbitrage pricing, see Delbaen \& Schachermayer (1998). By the supermartingale property (3.2) of the normalized benchmarked savings account process $\Lambda=\left\{\Lambda_{t_{n}}, n \in\{0,1, \ldots\}\right\}$ it follows from (4.6) that $1=\Lambda_{0} \geq E_{0}\left(\Lambda_{t_{N}}\right)$. Together with equation (4.6) this yields the inequality

$$
S_{0}^{\delta_{H}} \leq \frac{E_{0}\left(\Lambda_{T} \frac{B_{0}}{B_{T}} H_{T}\right)}{E_{0}\left(\Lambda_{T}\right)} .
$$

Equality holds in relation (4.7) only under the unrealistic assumption that the 


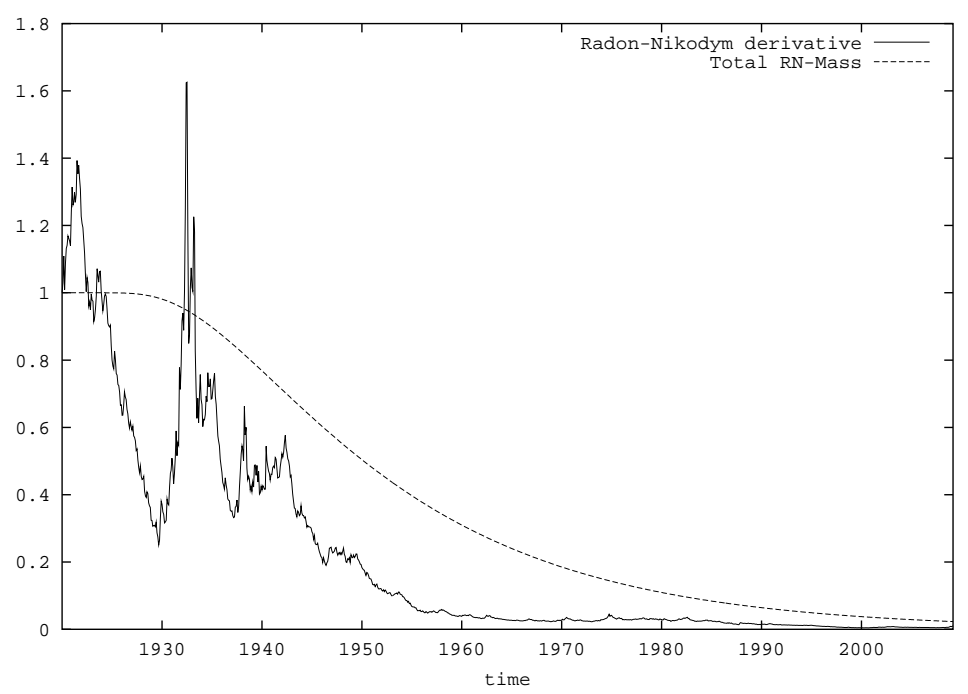

Figure 4.2: Radon-Nikodym derivative and total mass of putative risk neutral measure in dependence on time $T$.

savings account is fair and the density process $\Lambda$ of the putative risk neutral measure $Q_{T}$ is a martingale. In this particular case the expression on the right hand side of (4.7) is the conditional expectation of the discounted contingent claim under the assumed equivalent risk neutral probability measure $Q_{T}$ with Radon-Nikodym derivative $\Lambda_{T}=\frac{d Q_{T}}{d P}$ by an application of Bayes' formula. Only in this case can the relation (4.7) yield the classical risk neutral price

$$
S_{0}^{\delta_{H}}=\frac{E_{0}\left(\Lambda_{T} \frac{B_{0}}{B_{T}} H_{T}\right)}{E_{0}\left(\Lambda_{T}\right)}=E_{0}^{Q_{T}}\left(\frac{B_{0}}{B_{T}} H_{T}\right),
$$

for a contingent claim $H_{T}$, see Ross (1976) and Harrison \& Kreps (1979). Here $E_{0}^{Q_{T}}$ denotes the conditional expectation under the assumed equivalent risk neutral probability measure $Q_{T}$. In this particular case, risk neutral pricing is also equivalent to pricing with a stochastic discount factor, see Cochrane (2001). As long as an equivalent risk neutral probability measure exists, several other classical pricing approaches are also consistent with (4.3). This applies to the use of a state-price density, see Constantinides (1992), or pricing kernel, see Ingersoll (1987). Similar is the use of a deflator, see Duffie (2001), or numéraire portfolio, see Long (1990) or Becherer (2001).

The martingale assumption for the density process underpins the classical noarbitrage pricing approach. If this crucial assumption is violated, then the expected excess return of the S\&P500 over the savings account, namely the equity premium, is ignored. It follows that risk neutral prices obtained by calculating the right hand side of the inequality (4.7) can be substantially higher than the corresponding real world prices on the left hand side of (4.7). This will be demonstrated in the examples presented in Sections 5 and 6. Of course, the real world price of a claim is the lowest price only if one does not change the underlying dynamics in such a comparison. 
Now, let us consider the pricing of nonhedgable contingent claims. Recall that a conditional expectation can be interpreted as a least squares projection of future random variables into currently observable random variables, see Kallianpur (1980) or Shiryaev (1984). Consequently, the real world pricing formula (4.3) provides, with its conditional expectation, the least squares projection of a given benchmarked contingent claim into the set of possible current benchmarked prices. Since in a least squares projection the forecasting error has mean zero and minimal variance, see Kallianpur (1980), also the benchmarked hedge error has exactly mean zero and achieves minimal variance.

The benchmarked hedge errors of benchmarked contingent claims can be pooled in an insurance company or bank and, thus, can be removed via diversification. More precisely, if these errors are generated by sufficiently many independent sources of uncertainty, a situation which can be achieved in a large institution, then via the Law of Large Numbers it follows that the total benchmarked replication error has not only mean zero, it has also a variance that vanishes asymptotically with an increasing number of independent sources of uncertainty. Large insurance companies or banks can make the market asymptotically complete by pooling benchmarked hedge errors. This means that real world pricing makes perfect sense for nonhedgable claims from the perspective of a diversified institution. Higher prices than real world prices would make the company less competitive and lower prices would not be sustainable for the institution in the long run.

Finally, note that utility indifference pricing, in the sense of Davis (1997), has been shown in Platen \& Heath (2006) for unhedgable contingent claims to be consistent with the real world pricing formula (4.3). This means that the particular choice of the utility function and the underlying market dynamics do not matter. In the light of the previous discussion this makes good sense and is also a satisfactory theoretical insight.

\section{Pricing a Long Term Zero Coupon Bond}

Now, let us use the US equity market to illustrate real world pricing by providing a realistic example for a long term zero coupon bond. We use the US 90 Day T Bill Rate as the short rate for the savings account. For the S\&P500 total return index, our benchmark portfolio, we employ monthly S\&P500 total return data, provided by Thomson Financial and Global Financial Data for the period from January 1920 until March 2009. The savings account discounted S\&P500 total return index was displayed in Figure 4.1.

For simplicity, we assume that the short rate is deterministic. By making the short rate random we would only complicate the exposition. However, we would obtain very similar (and even slightly more pronounced) results, due to the effect of stochastic interest rates on bond prices as a consequence of Jensen's inequality. 
A similar comment applies to the choice of the S\&P500 total return index, as numéraire portfolio. It is likely that there exist other diversified portfolios which are better proxies for the numéraire portfolio, see Le \& Platen (2006). These would, however, exhibit an even larger long term trend and the price difference we will demonstrate would be even stronger.

Let $D\left(t_{n}, T\right)=\frac{B_{t_{n}}}{B_{t_{N}}}$ denote the price at time $t_{n}, n \in\{0,1, \ldots, N\}$, of the, socalled, savings bond with maturity $T=t_{N}$, where $B_{t_{n}}$ denotes again the savings account. Its logarithm is shown as the upper graph in Figure 5.1, whereas its benchmarked value is displayed as the upper graph in Figure 5.2. As already

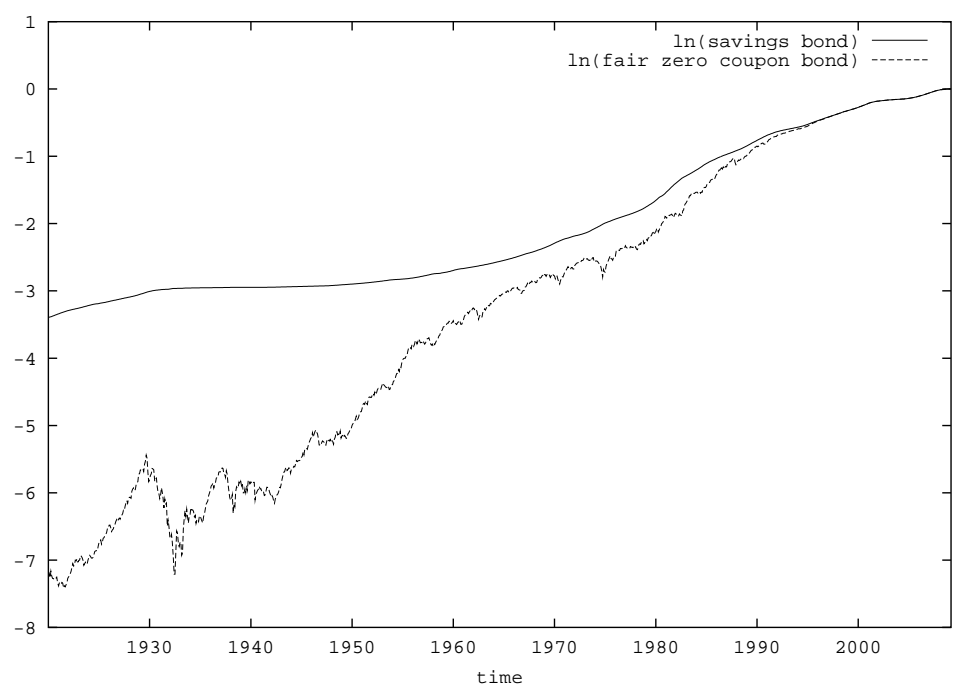

Figure 5.1: Logarithms of savings bond and fair zero coupon bond.

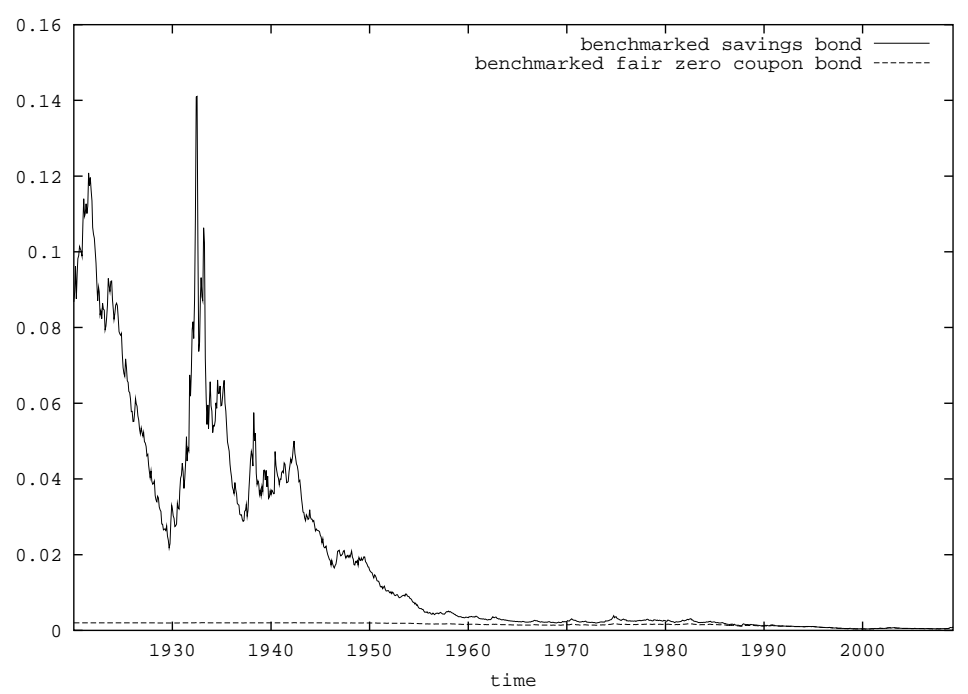

Figure 5.2: Benchmarked savings bond and benchmarked fair zero coupon bond.

noted in Figure 4.2, the benchmarked savings account, and therefore, the benchmarked savings bond, show a systematic downward trend. Consequently, by our 
previous discussion, an equivalent risk neutral probability measure is unlikely to exist in any realistic complete market model. We emphasize that the observed systematic long term negative trend of the benchmarked savings bond in Figure 5.2 simply reflects the presence of the equity premium and, thus, makes economic sense. This premium is the reason why investors hold stocks for long term investment and, thus, the economic basis for the existence of the stock market. We argue in this paper that its presence has to be properly modeled in the long term.

Now, let us price at time $t_{n}$ a zero coupon bond with maturity $T$. The fair zero coupon bond price

$$
P\left(t_{n}, T\right)=S_{t_{n}}^{*} E_{t_{n}}\left(\frac{1}{S_{T}^{*}}\right)
$$

results from the real world pricing formula (4.3), see also (4.5). It provides the minimal price for a portfolio that aims to replicate $\$ 1$ at maturity $T$. Note that under real world pricing the fair zero coupon bond becomes an index derivative. The underlying assets are the benchmark (here the S\&P500 total return index) and the savings account, which will both appear in a corresponding hedge portfolio.

To determine the price of a fair zero coupon bond, one has to compute the conditional expectation in (5.1). For this calculation one needs a realistic model for the real world distribution of the random variable $\left(S_{T}^{*}\right)^{-1}$. Recall that the initial price in 1920 of the benchmarked savings bond with maturity in 2009 is shown in Figure 5.2. Due to the presence of the equity premium for an extreme term to maturity $T$ it is clear that the probability mass of the distribution for one benchmarked dollar $\left(S_{T}^{*}\right)^{-1}$ should be concentrated much closer to zero than the initial benchmarked price of the savings bond. Any realistic model that takes the systematic downward trend of the benchmarked savings bond into account, will value the above benchmarked fair zero coupon bond in 1920 much lower than the corresponding benchmarked savings bond. There is also an economic explanation for this. The savings bond gives the holder the right to exit the contract at any time without penalty. A fair zero coupon is a fixed term deposit without this right and an exit would cause severe penalties. In this sense the savings bond carries a liquidity premium, which makes it more expensive.

The benchmarked fair zero coupon is the best forecast of its benchmarked payoff $\left(S_{T}^{*}\right)^{-1}$. To facilitate a tractable evaluation of a fair zero coupon bond we employ a discretely observed continuous time model for the benchmarked savings account. The inverse of the benchmarked savings account is the discounted numéraire portfolio $\bar{S}_{t}^{*}=\frac{S_{t}^{*}}{B_{t}}$. It satisfies in a continuous market model the stochastic differential equation

$$
d \bar{S}_{t}^{*}=\alpha_{t} d t+\sqrt{\bar{S}_{t}^{*} \alpha_{t}} d W_{t}
$$

for $t \geq 0$ with $\bar{S}_{0}^{*}>0$, see Platen \& Heath (2006). Here $W=\left\{W_{t}, t \geq 0\right\}$ is a Wiener process, and $\alpha=\left\{\alpha_{t}, t \geq 0\right\}$ is a strictly positive process, which models 
the trend $\alpha_{t}$ of $\bar{S}_{t}^{*}$ the discounted benchmark portfolio. This trend can be interpreted as the discounted "fundamental" value of wealth that is generated per unit of time by the companies traded in the equity market. In a first approximation one can assume that the discounted S\&P500 total return index grows exponentially. If at time $t$ the trend of the discounted S\&P500 total return index $\bar{S}_{t}^{*}$ is modeled by an exponential function $\alpha_{t}=\alpha \exp \{\eta t\}$, then the stylized version of the minimal market model (MMM) emerges from (5.2), see Platen (2001, 2002). Since we know explicitly the transition density of the diffusion process $\bar{S}^{*}$, see Platen (2002), this gives us the distribution of $\left(S_{T}^{*}\right)^{-1}$. Under the MMM the benchmarked savings bond is not fair. It is the inverse of a time-transformed squared Bessel process of dimension four and, therefore, a strict supermartingale, see Revuz \& Yor (1999). Its strict supermartingale property captures the presence of the equity premium in the real market. A reflection of this is given in Figure 4.2, which also displays its expected (Radon-Nikodym derivative) density process $\Lambda$. The conditional expectation

$$
E_{0}\left(\Lambda_{T}\right)=1-\exp \left\{-\frac{2 \eta \bar{S}_{0}^{*}}{\alpha(\exp \{\eta T\}-1)}\right\}
$$

equals the total mass

$$
Q_{T}(\Omega)=E_{0}^{Q_{T}}\left(\mathbf{1}_{\{\omega \in \Omega\}}\right)=E_{0}\left(\Lambda_{T} \mathbf{1}_{\{\omega \in \Omega\}}\right)=E_{0}\left(\Lambda_{T}\right)
$$

of the putative risk neutral measure $Q_{T}$ under the MMM. Here $\mathbf{1}_{\{\omega \in \Omega\}}$ denotes the indicator function for the event $\omega$ to be part of the set of all events $\Omega$. Since $Q_{T}(\Omega)<1$ for $T>0$, the putative risk neutral measure is not a probability measure. This is also the case for any other model where the benchmarked savings account is a strict supermartingale.

Fitting the logarithm of the observed discounted S\&P500 total return index by standard linear regression yields an estimate of about 0.054 for the net growth rate $\eta$. This is consistent with estimates from various other sources where the growth rate of the US equity market above the interest rate during the last century has been estimated close to 5\%, see for instance Dimson, Marsh \& Staunton (2002). The second parameter of the MMM is the scaling parameter $\alpha$, which can also be estimated via linear regression. For this purpose one can exploit the fact that the slope of the estimated quadratic variation of the square root of the normalized index $Y_{t_{n}}=\frac{\bar{S}_{t_{n}}^{*}}{\alpha_{t_{n}}}$ theoretically equals 0.25 , see Platen \& Heath (2006). Such linear regression produces for the given monthly data an estimate of $\alpha \approx 0.01468$, where the initial value $\bar{S}_{0}^{*}$ in January 1920 of the discounted S\&P500 was equal to 0.3865 .

Under the stylized MMM the transition density of the discounted numéraire portfolio $\bar{S}_{t_{n}}^{*}$ is explicitly known and yields for the fair zero coupon bond price by (5.1) the explicit formula

$$
P\left(t_{n}, T\right)=D\left(t_{n}, T\right)\left(1-\exp \left\{-\frac{2 \eta \bar{S}_{t_{n}}^{*}}{\alpha\left(\exp \{\eta T\}-\exp \left\{\eta t_{n}\right\}\right)}\right\}\right)
$$


for $0 \leq t_{n} \leq T<\infty$, see Platen \& Heath (2006). Figure 5.2 displays with the lower graph the evolution of the benchmarked fair zero coupon bond price with maturity $T$ in March 2009. By (5.3) the price of the benchmarked fair zero coupon bond always remains below that of the benchmarked savings bond. The latter can be interpreted as the risk neutral zero coupon bond price. Under the MMM only the fair zero coupon bond provides (with its current benchmarked value) the best forecast for its future benchmarked payoff of one benchmarked US dollar at maturity. It represents the minimal price process for the given payoff. All other benchmarked replicating portfolios that may be feasible have some downward trend. One example is given by the benchmarked savings bond. Recall that the benchmarked fair zero coupon bond is a martingale. Therefore, it is minimal among the supermartingales formed by benchmarked replicating portfolios.

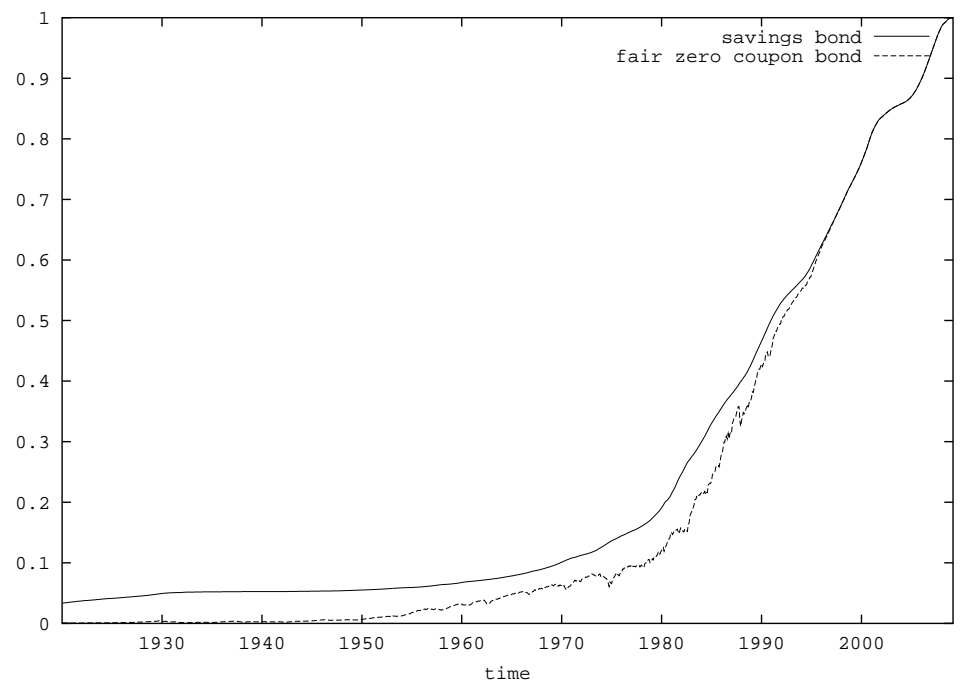

Figure 5.3: Savings bond and fair zero coupon bond.

Figure 5.3 exhibits with its upper graph the price evolution of the savings bond and with its lower graph that of the fair zero coupon bond in US dollar denomination. Closer to maturity the fair zero coupon bond follows the trajectory of the savings bond almost perfectly. Both self-financing portfolios replicate the payoff at maturity. However, they start with significantly different initial prices. The presence of two self-financing replicating portfolios is possible under the benchmark approach. Note that this contradicts classical no-arbitrage assumptions and the classical Law of One Price.

As indicated earlier, there is an additional difference between both self-financing portfolios that the classical no-arbitrage paradigm does not allow: namely the fair zero coupon bond is a term deposit which delivers the payoff of $\$ 1$ at maturity, where no intermediate access is permitted to its value. On the other hand, the savings bond can be interpreted as the limit of a roll-over short term bond account where the terms to maturity vanish. It can be liquidated at any trading time without any extra costs. Therefore, one could say that some liquidity premium makes the savings bond more expensive than the fair zero coupon bond. We see 
in Figure 5.3 that this liquidity premium can have a significant impact on the price of a bond over long time periods. Obviously, the liquidity premium vanishes when the time to maturity vanishes.

In our example, the savings bond with maturity in March 2009 had in January 1920 a price of $D(0, T) \approx \$ 0.0335$. The fair zero coupon bond was far less expensive and priced at only $P(0, T) \approx \$ 0.00077$. The fair zero coupon bond with term to maturity of about 88 years costs less than $2.3 \%$ of the savings bond. This reveals a substantial liquidity premium for always allowing access to the invested wealth.

Figure 5.2 illustrates that any model, which captures reasonably well the distribution of the benchmarked payoff $\frac{1}{S_{T}^{*}}$, would yield a similar small initial benchmarked fair zero coupon bond price. There is significant robustness in the modeling under the benchmark approach. Figure 5.1 illustrates this by showing the logarithms of the savings bond and the fair zero coupon bond. Most important is the fact that the fair zero coupon bond initially follows the S\&P500 total return index and exploits, in this way, the presence of the equity premium. Closer to maturity, the trajectory of the fair zero coupon bond slides into that of the savings bond. The strategy by which this is achieved in Figures 5.1-5.3 is a consequence of the explicit zero coupon bond pricing formula obtained under the MMM. It facilitates what financial planning has always suggested for life cycle investment, which cannot be explained under the classical no-arbitrage pricing paradigm.

To demonstrate how realistic the hedge of the fair zero coupon bond payoff is under the simple MMM for monthly reallocation, we form a self-financing hedge portfolio. At the trading time $t_{i}$ the corresponding theoretical number of units of the S\&P500 to be held in the hedge portfolio is given by the formula

$$
\begin{aligned}
\delta_{t_{i}}^{*} & =\frac{\partial \bar{P}\left(t_{i}, T\right)}{\partial \bar{S}_{t_{i}}^{*}} \\
& =D(0, T) \exp \left\{\frac{-2 \eta \bar{S}_{t_{i}}^{*}}{\alpha\left(\exp \{\eta T\}-\exp \left\{\eta t_{i}\right\}\right)}\right\} \frac{2 \eta}{\alpha\left(\exp \{\eta T\}-\exp \left\{\eta t_{i}\right\}\right)},
\end{aligned}
$$

see Platen \& Heath (2006). The remaining wealth is kept in the savings account $B_{t_{i}}$. We perform a delta hedge similar to the one known for options under the Black-Scholes model. The self-financing hedge portfolio started in January 1920. Each month the fraction invested in the S\&P500 was adjusted, in a self-financing manner, according to the above prescription. The resulting maximum absolute benchmarked profit and loss for this delta hedge turned out to be very small, and amounted only to about 0.00006 . This benchmarked hedge error is so small that the resulting hedge portfolio, when additionally plotted in Figure 5.3, would not be distinguishable from the path of the displayed fair zero coupon bond price process. 


\section{Pricing a Long Term European Put}

Variable annuities often have guarantees with option type payoffs on an index. Therefore, let us consider another long term derivative under the MMM. This second example is the fair price $p\left(t_{n}, S_{t_{n}}^{*}, T, K, r\right)$ at time $t_{n} \in\left\{t_{0}, t_{1}, \ldots, t_{N}\right\}$ of a European put option on the benchmark, the S\&P500 total return index denoted by $S_{T}^{*}$, with strike $K$ and maturity $T=t_{N}$. For simplicity, we assume a constant short rate $r$. The fair price of the put is according to (4.3) given by the real world expectation

$$
p\left(t_{n}, S_{t_{n}}^{*}, T, K, r\right)=S_{t_{n}}^{*} E_{t_{n}}\left(\frac{\left(K-S_{T}^{*}\right)^{+}}{S_{T}^{*}}\right),
$$

and can be calculated explicitly via the formula

$$
p\left(t_{n}, S_{t_{n}}^{*}, T, K, r\right)=-S_{t_{n}}^{*} \chi^{2}\left(d_{1} ; 4, l_{2}\right)+K e^{-r\left(T-t_{n}\right)}\left(\chi^{2}\left(d_{1} ; 0, l_{2}\right)-\exp \left\{-l_{2} / 2\right\}\right),
$$

with

$$
d_{1}=\frac{4 \eta K \exp \left\{-r\left(T-t_{n}\right)\right\}}{B_{t_{n}} \alpha_{t_{n}}\left(\exp \left\{\eta\left(T-t_{n}\right)\right\}-1\right)}
$$

and

$$
l_{2}=\frac{4 \eta S_{t_{n}}^{*}}{B_{t_{n}} \alpha_{t_{n}}\left(\exp \left\{\eta\left(T-t_{n}\right)\right\}-1\right)},
$$

see Platen \& Heath (2006). Here $\chi^{2}(x ; \nu, l)$ is the non-central chi-square distribution function with $\nu \geq 0$ degrees of freedom and non-centrality parameter $l>0$, i.e.

$$
\chi^{2}(x ; \nu, l)=\sum_{k=0}^{\infty} \frac{\exp \left\{-\frac{l}{2}\right\}\left(\frac{l}{2}\right)^{k}}{k !}\left(1-\frac{\Gamma\left(\frac{x}{2} ; \frac{\nu+2 k}{2}\right)}{\Gamma\left(\frac{\nu+2 k}{2}\right)}\right),
$$

see Platen \& Heath (2006). The risk neutral put price under the putative risk neutral measure $Q$ is higher than the fair put price, and the difference can be shown to amount to

$$
K e^{-r\left(T-t_{n}\right)} \exp \left\{-\frac{2 \eta \bar{S}_{t_{n}}^{*}}{\alpha\left(\exp \{\eta T\}-\exp \left\{\eta t_{n}\right\}\right)}\right\}
$$

see Platen \& Heath (2006). It can be seen from the fair put formula (6.1) that when the numéraire portfolio $S_{t_{n}}^{*}$ becomes very small, the fair put value is also very small. For a very small value $\bar{S}_{t_{n}}^{*}$ a put price derived under the risk neutral pricing paradigm would be significantly larger than the fair put price by an amount of approximately $K e^{-r\left(T-t_{n}\right)}$, as follows from (6.2).

In Figure 6.1 we show on logarithmic scale with the upper graph the evolution of a savings bond with face value $K=1500$ with the middle graph, a formally obtained risk neutral put price and with the lower graph a fair put price. One notes that the long term risk neutral put price (the middle graph) evolves initially like $K$ times the savings bond. The logarithm of the fair put price, exhibited as lower graph, behaves initially much like the logarithm of the S\&P500 total return 


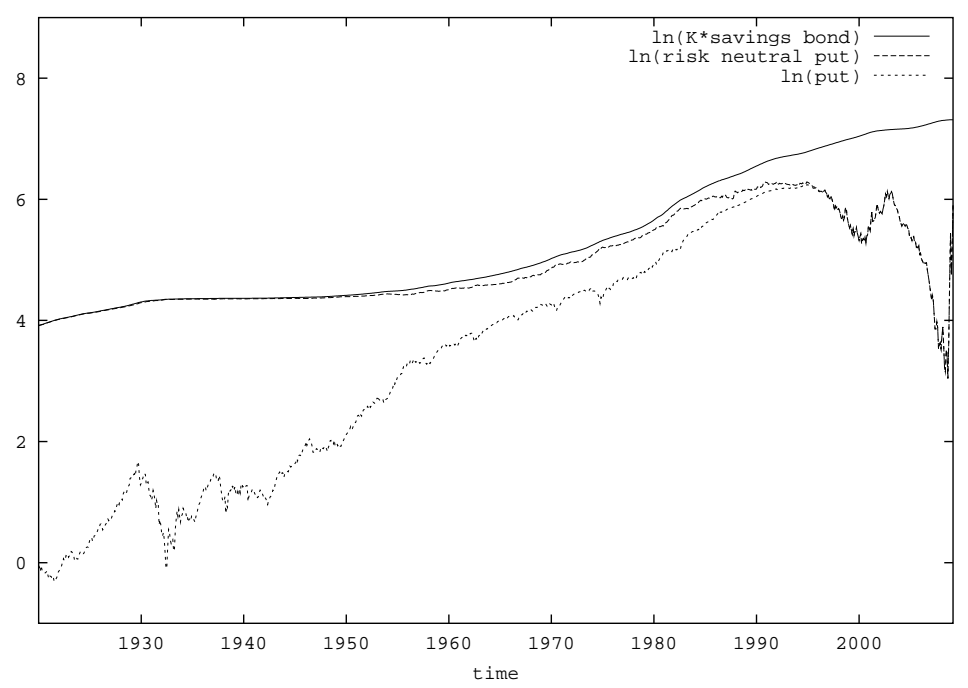

Figure 6.1: Logarithms of $K$ times savings bond, risk neutral put and fair put.

index and exploits in this way the presence of the equity premium. Closer to maturity the fair put price finally merges with the risk neutral put price and converges to the put payoff. This strategy is facilitated by the above explicit fair put pricing formula. A corresponding delta hedge in the S\&P500 and the savings account, similar to the one for the fair zero coupon bond, also replicates the given put payoff, see Hulley \& Platen (2008). We emphasize that the initial fair put price turns out to be substantially lower than the corresponding formally obtained risk neutral put price.

One can say that by shifting the pricing paradigm from risk neutral to real world pricing, one is able to replicate more cost efficient payoffs which have to be delivered far in the future. More precisely, one can expect savings to arise for payoffs that do not vanish when the benchmark approaches zero, see Platen \& Heath (2006). This applies to a range of payoffs that are typically embedded in variable annuities including puts and bonds. Many variable annuities can be less expensively hedged than suggested by most of the literature that was discussed in Section 2. It is beyond the scope of this paper to go into any details of the pricing of particular variable annuities under the benchmark approach. An illustration of the valuation of a guaranteed minimum death benefit under real world pricing is given in Marquardt, Platen \& Jaschke (2008).

\section{Conclusion}

The paper proposes a move away from risk neutral pricing towards the more general real world pricing of long dated contingent claims. Such an approach allows the presence of the equity premium and does not assume the existence of an equivalent risk neutral probability measure. As a consequence, the resulting 
real world prices can be much lower than those obtained under the classical risk neutral paradigm. Additionally, it has been pointed out that pricing by hedging may not yield the minimal possible price. The proposed real world pricing uses the numéraire portfolio and the real world probability when forming expectations. It identifies the minimal price for a contingent claim, while its hedge error can be removed via diversification in a large pool of claims. Real world pricing generalizes classical risk neutral pricing but also actuarial pricing in natural ways. Examples for the pricing of long dated zero coupon bonds and European puts illustrate how cost efficient real world prices of long term contracts are when compared to classical risk neutral prices.

\section{Acknowledgement}

The author thanks Hans Bühlmann, Carl Chiarellla, Kristoffer Glover, Hardy Hulley and Terry Walter for their comments on this work, and Stefan Jaschke, Martina Marquardt and Stefan Reulein at Münchener Rückversicherungs Gesellschaft for stimulating discussions on the application of real world pricing to variable annuities. Furthermore, he thanks the organizers of the ERM 2009 Symposium in Chicago for their interest in the benchmark approach, which stimulated the writing of this paper. The data for the S\&P500 were provided by Datastream Thomson Financial and Global Financial Data.

\section{References}

Aase, K. K. \& S. A. Persson (1994). Pricing of unit-linked life insurance with endogenous minimum guarantees. Scandinavian Actuarial J. 1, 26-52.

Albizzati, M. O. \& H. Geman (1994). Interest rate risk management and valuation of the surrender option in life insurance policies. J. of Risk and Insurance 61(4), 616-637.

Babbel, D. F. \& C. Merrill (1998). Economic valuation models for insurers. North American Actuarial J. 2(3), 1-15.

Bacinello, A. R. (2001). Fair pricing of life insurance participating policies with a minimum interest rate guaranteed. ASTIN Bulletin 31(2), 275-297.

Bacinello, A. R. (2005). Endogenous model of surrender conditions in equitylinked life insurance. Insurance: Mathematics and Economics 37, 270-296.

Bacinello, A. R. \& F. Ortu (1993). Pricing equity-linked life insurance with endogenous minimum guarantees. Insurance: Mathematics and Economics 12, 245-257.

Bacinello, A. R. \& F. Ortu (1994). Single and periodic premiums for guaranteed equity-linked life insurance under interest-rate risk: The "Lognormal + 
Vasicek" Case. In L. Peccati and M. Viren (Eds.), Financial Modelling, pp. 1-55. Physica-Verlag.

Bacinello, A. R. \& F. Ortu (1996). Fixed income linked life insurance policies with minimum guarantees: Pricing models and numerical results. European Journal of Operational Research 91, 235-249.

Bajeux-Besnainou, I. \& R. Portait (1997). The numeraire portfolio: A new perspective on financial theory. The European Journal of Finance 3, 291309.

Ballotta, A. R. (2004). Alternative framework for the fair valuation of participating life insurance contracts. Working paper, Cass Business School, City University London.

Ballotta, A. R., S. Haberman, \& N. Wang (2003). Guarantees in with-profit and unitized with-profit life insurance contracts fair valuation problem in presence of the default option. Working paper, Cass Business School, City University London.

Bauer, D., A. Kling, \& J. Russ (2007). Ein allgemeines Model zur Analyse und Bewertung von guaranteed minimum Benefits in Fondspolicen. Blaetter der DGVFM 28(2), 259-290.

Becherer, D. (2001). The numeraire portfolio for unbounded semimartingales. Finance Stoch. 5, 327-341.

Bernard, G. A. (1993). A direct approach to pricing death benefit guarantees in variable annuity products. Product Development News June, 6-8.

Biffis, E. (2005). Affine processes for dynamic mortality and actuarial valuations. Insurance: Mathematics and Economics 37, 443-468.

Biffis, E. \& P. Millosovich (2006). The fair value of guaranteed annuity options. Scandinavian Actuarial J. 1, 23-41.

Bilodeau, C. (1997). Better late than never: The case of the rollover option. Insurance: Mathematics and Economics 21, 103-111.

Black, F. \& M. Scholes (1973). The pricing of options and corporate liabilities. J. Political Economy 81, 637-654.

Boyle, P. P. \& M. R. Hardy (1997). Reserving for maturity guarantees: Two approaches. Insurance: Mathematics and Economics 21, 113-127.

Boyle, P. P. \& M. R. Hardy (2003). Guaranteed annuity options. ASTIN Bulletin 33(2), 125-152.

Boyle, P. P., A. Kolkiewicz, \& K. Tan (2001). Valuation of the reset options embedded in some equity linked insurance products. North American Actuarial J. 5, 1-18.

Boyle, P. P. \& E. S. Schwartz (1977). Equilibrium prices of guarantees under equity-linked contracts. J. of Risk and Insurance 44, 639-680. 
Brennan, M. J. \& E. S. Schwartz (1976). The pricing of equity linked life insurance policies with an asset value guarantee. J. Financial Economics 3, $195-213$.

Brennan, M. J. \& E. S. Schwartz (1979). A continuous time approach to the pricing of bonds. J. Banking and Finance 3, 133-155.

Briys, E. \& F. Varenne (1997). On the risk of life insurance liabilities: Debunking some common pitfalls. J. of Risk and Insurance 64, 37-57.

Bühlmann, H. \& E. Platen (2003). A discrete time benchmark approach for insurance and finance. ASTIN Bulletin 33(2), 153-172.

Cairns, A. J. (2001). From financial economics to fair valuation. In Proceedings of the 11th International AFIR Colloquium, Toronto, September 2001, Volume 1, pp. 135-166.

Cairns, A. J., D. Blake, \& K. Dowd (2006a). Pricing death: Frameworks for the valuation and securitization of mortality risk. ASTIN Bulletin 36(1), 79-120.

Cairns, A. J., D. Blake, \& K. Dowd (2006b). A two-factor model for stochastic mortality with parameter uncertainty: Theory and calibration. J. of Risk and Insurance 73, 687-718.

Cairns, A. J., D. Blake, \& K. Dowd (2008). Modelling and management of mortality risk: A review. Scandinavian Actuarial J. 2-3, 79-113.

Cerny, A. \& S. D. Hodges (1999). The theory of no-good-deal pricing in financial markets. Imperial College (working paper).

Chu, C. C. \& Y. K. Kwok (2006). Pricing participating policies with rate guarantees. Int. J. Theor. Appl. Finance 9, 517-532.

Chu, C. C. \& Y. K. Kwok (2007). Valuation of guaranteed annuity options in affine term structure models. Int. J. Theor. Appl. Finance 10(2), 363-387.

Cochrane, J. H. (2001). Asset Pricing. Princeton University Press.

Constantinides, G. M. (1992). A theory of the nominal structure of interest rates. Rev. Financial Studies 5, 531-552.

Costabile, M., I. Massabo, \& E. Russo (2007). A binomial model for valuing equity-linked policies embedding surrender options. Insurance: Mathematics and Economics 42(3), 873-886.

Dahl, M. (2004). Stochastic mortality in life insurance: Market reserves and mortality-linked insurance contracts. Insurance: Mathematics and Economics 35, 113-136.

Dahl, M. \& T. Möller (2006). Valuation and hedging life insurance liabilities with systematic mortality risk. Insurance: Mathematics and Economics 39, 193-217. 
Davis, M. H. A. (1997). Option pricing in incomplete markets. In M. A. H. Dempster and S. R. Pliska (Eds.), Mathematics of Derivative Securities, pp. 227-254. Cambridge University Press.

De Felice, M. \& F. Moriconi (2005). Market based tools for managing the life insurance company. ASTIN Bulletin 1, 79-111.

Debreu, G. (1982). Existence of competitive equilibrium. In K. Arrow and M. Intrilligator (Eds.), Handbook of Mathematical Economics, Volume II, pp. 697-743. North Holland, Amsterdam.

Delbaen, F. (1986). Equity-linked policies. Bull. Assoc. Royal Actuaries Belges 80, 33-52.

Delbaen, F., P. Grandits, T. Rheinländer, D. Samperi, M. Schweizer, \& C. Stricker (2002). Exponential hedging and entropic penalties. Math. Finance 12(2), 99-123.

Delbaen, F. \& W. Schachermayer (1998). The fundamental theorem of asset pricing for unbounded stochastic processes. Math. Ann. 312, 215-250.

Dimson, E., P. Marsh, \& M. Staunton (2002). Triumph of the Optimists: 101 Years of Global Investment Returns. Princeton University Press.

Duffie, D. (2001). Dynamic Asset Pricing Theory (3rd ed.). Princeton, University Press.

Duffie, D. \& H. R. Richardson (1991). Mean-variance hedging in continuous time. Ann. Appl. Probab. 1, 1-15.

Ekern, S. \& S. A. Persson (1996). Exotic unit-linked life insurance contracts. The Geneva Papers on Risk and Insurance Theory 21, 35-63.

Föllmer, H. \& P. Leukert (1999). Quantile hedging. Finance Stoch. 3, 251-273.

Föllmer, H. \& P. Leukert (2000). Efficient hedging: Cost versus shortfall risk. Finance Stoch. 4, 117-146.

Föllmer, H. \& M. Schweizer (1991). Hedging of contingent claims under incomplete information. In M. H. A. Davis and R. J. Elliott (Eds.), Applied Stochastic Analysis, Volume 5 of Stochastics Monogr., pp. 389-414. Gordon and Breach, London/New York.

Föllmer, H. \& D. Sondermann (1986). Hedging of non-redundant contingent claims. In W. Hildebrandt and A. Mas-Colell (Eds.), Contributions to Mathematical Economics, pp. 205-223. North Holland.

Gerber, H. U. (1997). Life Insurance Mathematics. Springer, Berlin. 3rd edition.

Gerber, H. U. \& E. S. W. Shiu (1994). Option pricing by Esscher transforms. Trans. Soc. Actuaries 46, 99-140.

Girard, L. N. (2000). Market value of insurance liabilities: Reconciling the actuarial appraisal and option pricing methods. North American Actuarial J. 4(1), 31-49. 
Grosen, A. \& P. L. Jorgensen (1997). Valuations of early exercisable interest rate guarantees. J. of Risk and Insurance 64(3), 481-503.

Grosen, A. \& P. L. Jorgensen (2000). Fair valuation of life insurance liabilities: The impact of interest rate guarantees, surrender options, and bonus policies. Insurance: Mathematics and Economics 26, 37-57.

Grosen, A. \& P. L. Jorgensen (2002). Life insurance liabilities at market value: An analysis of insolvency risk, bonus policy, regulatory intervention rules in a barrier option framework. J. of Risk and Insurance 69(1), 63-91.

Hardy, M. (2003). Investment Guarantees: The New Science of Modeling and Risk Management for Equity-Linked Life Insurance. John Wiley \& Sons, Inc., Hoboken, New Jersey.

Harrison, J. M. \& D. M. Kreps (1979). Martingale and arbitrage in multiperiod securities markets. J. Economic Theory 20, 381-408.

Hodges, S. \& A. Neuberger (1989). Optimal replication of contingent claims under transaction costs. Rev. Futures Markets 8, 222-239.

Hofmann, N., E. Platen, \& M. Schweizer (1992). Option pricing under incompleteness and stochastic volatility. Math. Finance 2(3), 153-187.

Huang, H. \& A. J. G. Cairns (2004). Valuation and hedging of limited price indexed liabilities. British Actuarial J. 10, 627-663.

Huang, H. \& A. J. G. Cairns (2005). On the control of defined-benefit pension plans. Insurance: Mathematics and Economics 38, 113-131.

Hulley, H. \& E. Platen (2008). Hedging for the long run. Technical report, University of Technology, Sydney. QFRC Research Paper 214.

Hürlimann, W. (2004). Fair pricing using deflators and decrement copulas: The unit linked endowment approach. Blaetter der DGVFM 3, 421-437.

Ingersoll, J. E. (1987). Theory of Financial Decision Making. Studies in Financial Economics. Rowman and Littlefield.

Jaimungal, S. \& V. R. Young (2005). Pricing equity-linked pure endowments with risky assets that follow Levy processes. Insurance: Mathematics and Economics 36(3), 329-346.

Jalen, L. \& R. Mamon (2008). Valuation of contingent claims with mortality and interest rate risks. University of Western Ontario, (working paper).

Jaschke, J. \& U. Küchler (2001). Coherent risk measures and good-deal bounds. Finance Stoch. 5(2), 181-200.

Jorgensen, P. (2001). Life insurance contracts with embedded options: Valuation, risk management and regulation. J. Risk Finance 3(1), 19-30.

Jorgensen, P. (2004). On accounting standards and fair valuation of life insurance and pension liabilities. Scandinavian Actuarial J. 5, 372-394.

Kallianpur, G. (1980). Stochastic Filtering Theory. Springer. 
Karatzas, I. \& C. Kardaras (2007). The numeraire portfolio in semimartingale financial models. Finance Stoch. 11(4), 447-493.

Karatzas, I., S. E. Shreve, J. P. Lehoczky, \& G. Xu (1991). Martingale and duality methods for utility maximization in an incomplete market. SIAM J. Control Optim. 29, 702-730.

Kardaras, C. \& E. Platen (2008). Multiplicative approximation of wealth processes involving no-short-sale strategies via simple trading. Technical report, University of Technology, Sydney. QFRC Research Paper 240.

Keel, A. \& H. H. Müller (1995). Efficient portfolios in the asset liability context. ASTIN Bulletin 25, 33-48.

Kirch, M. \& A. V. Melnikov (2005). Efficient hedging and pricing life insurance policies in a jump-diffusion model. Stochastic Anal. Appl. 23(6), 1213-1233.

Kling, A., A. Richter, \& J. Russ (2007). The interaction of guarantees, surplus distribution and asset allocation in with-profit life insurance policies. Insurance: Mathematics and Economics 40, 164-178.

Kramkov, D. O. \& W. Schachermayer (1999). The asymptotic elasticity of utility functions and optimal investment in incomplete markets. Ann. Appl. Probab. 9, 904-950.

Krutchenko, R. N. \& A. V. Melnikov (2001). Quantile hedging for a jump-diffusion financial market. In Trends in Mathematics, pp. 215-229. Birkhäuser Verlag, Basel/Switzerland.

Lane, M. (2000). Pricing risk transfer functions. ASTIN Bulletin 30, 259-293.

Le, T. \& E. Platen (2006). Approximating the growth optimal portfolio with a diversified world stock index. J. Risk Finance 7(5), 559-574.

Long, J. B. (1990). The numeraire portfolio. J. Financial Economics 26, 29-69.

Longley-Cook, A. G. (1998). Risk-adjusted economic value analysis. North American Actuarial J. 2(1), 87-98.

Mandelbrot, B. \& J. W. Van Ness (1968). Fractional Brownian motions, fractional noises and applications. SIAM Rev. 10, 422-437.

Marquardt, T., E. Platen, \& J. Jaschke (2008). Valuing guaranteed minimum death benefit options in variable annuities under a benchmark approach. Technical report, University of Technology, Sydney. QFRC Research Paper 221.

Melnikov, A. V. (2003). Pricing of flexible insurance schemes. J. of Economics 7(2), 139-172.

Melnikov, A. V. (2004a). Efficient hedging of equity-linked life insurance policies. Doklady Mathematics 69, 462-464.

Melnikov, A. V. (2004b). Quantile hedging of equity-linked life insurance policies. Doklady Mathematics 69, 428-430. 
Melnikov, A. V. (2004c). Risk Analysis in Finance and Insurance. Chapman and Hall/ CRC Press.

Melnikov, A. V. \& Y. Romaniuk (2006). Evaluating the performance of Gompertz, Makeham and Lee-Carter mortality models for risk management with unit-linked contracts. Insurance: Mathematics and Economics 39, 310-329.

Melnikov, A. V.\& Y. Romaniuk (2008). Efficient hedging and pricing of equitylinked life insurance contracts on several risky assets. Int. J. Theor. Appl. Finance 11(3), 295-323.

Melnikov, A. V., Y. Romaniuk, \& V. S. Skornyakova (2005). Margrabe's formula and quantile hedging of life insurance contracts. Doklady Mathematics 71, 31-34.

Melnikov, A. V. \& V. S. Skornyakova (2005). Quantile hedging and its application to life insurance. Statistics and Decisions 23, 301-316.

Melnikov, A. V., S. N. Volkov, \& M. L. Nechaev (2002). Mathematics of Financial Obligations. American Mathematical Society, Providence, RI.

Merton, R. C. (1973). Theory of rational option pricing. Bell J. Econ. Management Sci. 4, 141-183.

Milevsky, M. A., K. S. Moore, \& V. R. Young (2006). Asset allocation and annuity-purchase strategies to minimize the probability of financial ruin. Math. Finance 16(4), 647-671.

Milevsky, M. A. \& S. E. Posner (2001). The Titanic option: Valuation of the guaranteed minimum death benefit in variable annuities and mutual funds. J. of Risk and Insurance 68(1), 93-128.

Milevsky, M. A. \& S. D. Promislow (2001). Mortality derivatives and the option to annuities. Insurance: Mathematics and Economics 29(3), 299-318.

Milevsky, M. A. \& T. S. Salisbury (2001). The real option to lapse and the valuation of death-protected investments. In Proceedings XI th AFIR Colloquium, pp. 537-563.

Milevsky, M. A. \& T. S. Salisbury (2006). Financial valuation of guaranteed minimum withdrawal benefits. Insurance: Mathematics and Economics 38, $21-38$.

Miltersen, K. \& S. A. Persson (1999). Pricing rate of return guarantees in a HJM framework. Insurance: Mathematics and Economics 25, 307-325.

Mitchell, G. T. (1994). Variable annuity minimum death benefits: A Monte Carlo pricing approach. Product Development News February, 10-13.

Möller, T. (1998). Risk-minimizing hedging strategies for unit-linked life insurance contracts. ASTIN Bulletin 28, 17-47.

Möller, T. (2001). Risk-minimizing hedging strategies for insurance payment processes. Finance Stoch. 5(4), 419-446. 
Möller, T. (2002). Hedging equity-linked life insurance contracts. North American Actuarial J. 5, 79-95.

Moore, K. \& V. Young (2003). Pricing equity-linked pure endowments via the principle of equivalent utility. Insurance: Mathematics and Economics 33, $497-516$.

Nielsen, J. A. \& K. Sandmann (1995). Equity-linked life insurance: A model with stochastic interest rates. Insurance: Mathematics and Economics 16, $225-253$.

Nielsen, J. A. \& K. Sandmann (1996). Uniqueness of the fair premium of the equity-linked life insurance contracts. The Geneva Papers on Risk and Insurance Theory 21, 65-102.

Nielsen, J. A. \& K. Sandmann (2008). The fair premium of an equity-linked life and pension insurance. University Bonn, Germany, (working paper).

Pelsser, A. (2003). Pricing and hedging guaranteed annuity options via static option replication. Insurance: Mathematics and Economics 33(2), 283-296.

Pennachi, G. G. (1999). The valuation of guarantees on pension fund returns. J. of Risk and Insurance 66(2), 219-237.

Persson, S. A. \& K. K. Aase (1997). Valuation of the minimum guaranteed return embedded in life insurance products. J. of Risk and Insurance 64(4), 599-617.

Phillips, R. D., J. D. Cummins, \& F. Allen (1998). Financial pricing of insurance in the multi-line insurance company. J. of Risk and Insurance 65, 597-636.

Platen, E. (2001). A minimal financial market model. In Trends in Mathematics, pp. 293-301. Birkhäuser.

Platen, E. (2002). Arbitrage in continuous complete markets. Adv. in Appl. Probab. 34(3), 540-558.

Platen, E. (2005). Diversified portfolios with jumps in a benchmark framework. Asia-Pacific Financial Markets 11(1), 1-22.

Platen, E. (2006). A benchmark approach to finance. Math. Finance 16(1), $131-151$.

Platen, E. \& D. Heath (2006). A Benchmark Approach to Quantitative Finance. Springer Finance. Springer.

Ravindran, K. \& W. Edelist (1996). Deriving benefits from death in frontiers. In A. Konishi and R. E. Dattatreya (Eds.), Derivatives: State-of-the-Art Models, Valuation, Strategies and Products. New York: McGraw Hill.

Reitano, R. R. (1997). Two paradigms for the market value of liabilities. North American Actuarial J. 1(4), 104-129.

Revuz, D. \& M. Yor (1999). Continuous Martingales and Brownian Motion (3rd ed.). Springer. 
Ross, S. A. (1976). The arbitrage theory of capital asset pricing. J. Economic Theory 13, 341-360.

Schmidli, H. (1995). Cramer-Lundberg approximations for ruin probabilities of risk processes perturbed by diffusion. Insurance: Mathematics and Economics 16(2), 135-149.

Schweizer, M. (1992). Mean-variance hedging for general claims. Ann. Appl. Probab. 2, 171-179.

Schweizer, M. (2001). From actuarial to financial valuation principles. Insurance: Mathematics and Economics 28, 31-47.

Shiryaev, A. N. (1984). Probability. Springer.

Siu, T. (2005). Fair valuation of participating policies with surrender options and regime switching. Insurance: Mathematics and Economics 37, 533-552.

Sloane, W. R. (1970). Life insurance, variable annuities and mutual funds: A critical study. J. of Risk and Insurance 37, 99.

Starr, R. M. (1997). General Equilibrium Theory: An Introduction. CUP, Cambridge.

Tanskanen, A. \& J. Lukkarinen (2003). Fair valuation of path-dependent participating life insurance contracts. Insurance: Mathematics and Economics 33, 595-609.

Tiong, S. (2000). Valuing equity-indexed annuities. North American Actuarial J. 4, 149-170.

Vannucci, E. (2003). An evaluation of the riskiness of unit linked policies with minimal return guarantees. In Proceedings of the VI Spanish-Italian Meeting on Financial Mathematics, pp. 569-582. Trieste.

Wang, S. S. (2000). A class of distortion operators for pricing financial and insurance risks. J. of Risk and Insurance 67, 15-36.

Wang, Y. (2009). Quantile hedging for guaranteed minimum death benefits. working paper, University of York, Canada, to appear in Insurance: Mathematics and Economics.

Wilkie, A. D. (1985). Portfolio selection in the presence of fixed liabilities: A comment on "The matching of assets to liabilities". J. Institute of Actuaries 112, 229-277.

Wilkie, A. D. (1987). An option pricing approach to bonus policy. J. Institute of Actuaries 114, 21-77.

Wilkie, A. D. (1995). More on a stochastic asset model for actuarial use (with discussion). British Actuarial J. 1, 777-964.

Windcliff, H., P. Forsyth, \& K. Vetzel (2001). Valuation of segregated funds: Shout options with maturity extensions. Insurance: Mathematics and Economics 29(1), 1-21. 
Wirch, J. L. \& M. R. Hardy (1999). A synthesis of risk measures for capital adequacy. Insurance: Mathematics and Economics 25, 337-347.

Wise, A. J. (1984a). The matching of assets to liabilities. J. Institute of Actuaries 111, 445-501.

Wise, A. J. (1984b). A theoretical analysis of the matching of assets to liabilities. J. Institute of Actuaries 111, 375-402.

Wise, A. J. (1987a). Matching and portfolio selection: Part I. J. Institute of Actuaries 114, 113-133.

Wise, A. J. (1987b). Matching and portfolio selection: Part II. J. Institute of Actuaries 114, 551-568.

Wise, A. J. (1989). Matching. J. Institute of Actuaries 116, 529-535.

Wüterich, M., H. Bühlmann, \& H. Furrer (2008). Market-Consistent Actuarial Valuation. EAA Lecture Notes. Springer.

Young, V. R. (2003). Euity-indexed life insurance: Pricing and reserving using the principle of equivalent utility. North American Actuarial J. 17(1), 6886.

Young, V. R. \& T. Zariphopoulou (2002). Pricing dynamic insurance risks using the principle of equivalent utility. Scandinavian Actuarial J. 4, 246-279. 